\title{
Enhancing Quality Services Delivery Through Staff Motivation at Kwame Nkrumah University
}

\author{
Joseph Kayuni Hachintu, PhD* \\ Directorate of Research and Postgraduate Studies, Kwame Nkrumah University - Zambia
}

*Corresponding Author: Joseph Kayuni Hachintu, PhD, Directorate of Research and Postgraduate Studies, Kwame Nkrumah University - Zambia

\begin{abstract}
This study assessed the delivery of Quality Services through motivation of staff at Kwame Nkrumah University in Zambia. The main aim of the study was to find out whether there were mechanisms put in place at the institution to incentivise employees, and whether the employees were motivated enough to deliver the required services. The study was anchored on Herzberg's Two-Factor Theory and other theories on workers' motivation, reinforcement and performance. Quota sampling technique has been used to select thirty (30) respondents drawn from the categories of academic staff and support staff. Data were collected using a Semistructured questionnaire while interview method was applied to the select few 'key' informants. It was found that the University had not devised adequate incentive mechanisms at the time of the study, and the majority of employees were not satisfied with the current situation. Part of the reasons advanced was that the institution had just come out of the massive transformation and mechanisms on incentives were yet to be put in place. The author's recommendations are that the university provides mechanism to give incentives to its employees as a top priority and that such incentives be administered contingent upon the employees' effective performance, in order to ensure that there is efficiency in service delivery.
\end{abstract}

Key words: Incentive; Motivation; Quality Services

\section{INTRODUCTION}

Kwame Nkrumah University was transformed from University College into full-fledged Public University in 2017. Among the many expectations of the general public at the time was that the transformation process would result in the recruitment and retention of well qualified teaching staff that would be incentivised enough to enable them deliver quality services up to the university standard. This study, therefore, sought to find out the mechanisms that were put in place and how they had motivated the teaching staff to deliver quality services at the institution. The paper is structured as follows: Section 2 presents a review of literature on staff motivation and efficient services delivery, Section 3 presents the Theoretical Frame work, Section 4 summarises the materials and methods used to collect the required data while Section 5 constitutes the results of the study and discusses the findings. Section 6 concludes the paper and offers recommendations from the study.

\section{LITERATURE REVIEW}

\subsection{Employee Compensation and Incentives}

Incentives are a common term applicable to all organisations whether they are non-profit making or for profit-making organisations. Employees in all organisations have some motivation of some kind for them to continue working for that organisation. Organisations have reward systems for their employees and the way employees are rewarded is starting to alter rapidly. This means that it is becoming important how an organisation recruits, trains, challenges and involves its workforce as these actions become critical components in ultimate organisational success. A clear understanding of the incentive structures in an organisation is critical to determine how individuals in that organisation behave and invariably perform their duties (Cole, 2002).

Chakraborty et.al. (2009) investigated the relationship between incentive compensation and performance related CEO turnover and found that "incentives and turnover are positively related". 
They stated that "our results suggest that high-powered incentives may increase the signaling power of performance measures and lead to higher likelihood of turnover". Although these studies were done at organisational top level involving CEOs, the principle still applies to indicate that incentives do contribute to improved employee performance in an organisation.

Chakraborty et.al. (2009) also considered the Innovative Employee Compensation Methods to Motivate Employees. In their view, most successful companies used at least some of the following motivating programmes:

i) Time off Surprise: Give Supervisors a bank of days and/or afternoons off that they can reward to staff on the spot for meritorious service. Variations of this programme include handing out cash bills or lunch coupons.

ii) Behind-the-Scenes: Recognise employees yearly or periodically who are not usually in the limelight. There is also an alternative one known as the Good Tries programme, which involves recognising employees who take risks, regardless of whether those risks result in failure or success.

iii) Cash for Ideas: Periodically hand out index cards and ask employees to record ways the company could save money. Pay a nominal amount per idea. If the idea is implemented, pay an additional $10 \%$ of the savings. The Poster Ideas programmes is somewhat similar. It involves hanging poster board at key locations within the company. Written at the top of each board is a problem that needs solving. Anyone can write their ideas in the space remaining on the poster.

There are also some suggested non-performance-based programmes that may be used to enhance performance. Examples of non-performance based programs include:

i) Core Hours: Give employees flexibility with regard to when they work on-site. For example, all employees could be required to be at work between 10:00 a.m. and 3:00 p.m. Beyond this general guideline, some employees may choose to arrive at 6:00 a.m. and leave at 3:00 p.m. Others may choose to start their day later and leave later.

ii) TIPS: (Tips for Improving Performance): Offer employees a 15- to 30-minute workshop on topics they need to enhance their professional and personal lives. Some topics might include handling difficult situations, goal-setting, dealing with change, nutrition, fitness and recycling. Attendance for these programs should be voluntary.

iii) Casual Dress programmes: Give staff a casual dress day once a week, during the entire summer, or on a permanent basis.

A third category of ideas to consider motivating employees and maximising performance are relationship-building programs. These incentives may not be viewed by some as compensation because there is no exchange of cash or merchandise, and no traditional or non-traditional benefits or perks. But such programs encompass a broad set of interactions which build camaraderie, open communication channels and break down organisational barriers - all of which are valued by employees and enhance their motivation and performance.

Studies have indicated that the most important deciding factor for accepting a job is open communications, which can be translated as healthy working relationships. The same factors that motivate people to start a job search will likely motivate them on the job as well. Examples of such relationship-building programmes include:

i) Executive Coffee Breaks: Institute a programme where the CEO and/or other top executives meet with all or small groups of staff for an hour or so over coffee. Although the discussion is free-flowing, employees are encouraged to send questions in advance.

ii) Stand by Me: A Chicago-area financial institution sponsors numerous radio advertisements promoting a programmes in which their executives spend a day outside the bank each year working side by side with their customers. This idea is one example of an effective relationships building internally as executives work side by side with staff.

iii) Orient the Family programmes: Sponsor a family orientation program for new staff which includes refreshments, office tours, a slide or video introduction to the organisation and dialogues 
with top executives. Follow up with family socials throughout the year. Many companies neglect to consider the influence that spouses and other family members have on employee satisfaction.

iv) Cooperative Charity Day: Give each department an annual day off to work with a local charity organisation. In the USA, Timberland is giving each employee 40 hours of paid time each year to work with local charities. In addition to the public relations value, such programmes build pride in the work force and serve to enhance internal relationships.

v) Special Dress Days: Planning special dress days to promote a sense of humor also enhances relationships. Examples might include Ugly Tie/Earrings, Crazy Sweater, Silly Socks, Hawaiian, and/or Halloween Costume Days, Prizes might be given for best costumes.

A study by the Ron Volper Group that was conducted in 2011 across a range of industries confirmed that the number one reason for "unforced turnover" is employee dissatisfaction with their compensation. Moreover, 80 percent of employees who voluntarily left their company took a higher paying position with another company (Ibid).

Small and mid-sized businesses that lose top performers incur the costs of hiring and training new employees, but they face an even greater risk: damaging relationships with existing customers and eroding the morale of other employees. Proof of this is that the companies that are the most profitable usually have the highest employee retention.

The research suggested the following use of the compensation plan to retain and motivate employees and up company sales in a down market:

i) Pay employees salary and incentives. The companies with the highest employee morale and productivity pay a mix of salary and incentives. The salary compensates employees for performing all the tasks required of them and provides them with a consistent income. The incentive (which can be commission for salespeople and a bonus for others) motivates them to meet and exceed their goals and gives them the opportunity to increase their earnings. Companies should pay employees the salary portion of their compensation monthly or bi-monthly. Pay employees the incentive portion of their compensation as soon after they meet their goals as feasible. Thus, quarterly incentive payments are usually more motivating than annual payments and monthly incentive payments are often best.

ii) Keep the incentive part of your plan simple. The test of a good compensation plan is that the incentive part measures no more than two to four performance factors, and all employees can accurately explain the plan, for example, in the time it takes to walk from the front door of your office building to your receptionist's desk.

iii) Establish SMART goals. SMART goals are: Specific, Measurable, Ambitious, Realistic and Time-bound.

For salespeople, that means establishing monthly and annual revenue goals and/or goals for opening new accounts. For other customer contact people, establish goals for the ratio of customer compliments versus complaints, and/or for instance, the number of customer complaints they resolve on the first phone call. For employees in accounts receivable, consider basing goals on how much outstanding revenue they collect against specific targets. For those in manufacturing, consider basing goals on the number of products they manufacture free of defects. While it's okay to pay a small part of the incentives based on the team's overall results, most of the incentive should be based on individual results.

iv) Determine what your competitors are paying. One way to attract and retain top employees-and keep them motivated is to pay them as much or more than your competitors. Every few years, you should determine what your competitors are paying and adjust your compensation plan accordingly. You can do this informally by asking employees with other companies that you interview about their compensation plan, or more objectively by hiring an outside consulting firm to benchmark your plan against others and advise you on how to adjust it.

v) Modify salaries based on employees' geographic location. While the incentive plan for employees working in different cities should not change, you should adjust the salary portion to reflect the local cost of living, so as not to penalise employees who live in more expensive cities. 
vi) Use merit increases to reward top performers. In a misguided attempt to keep all employees happy, many companies misallocate the funds they budget for annual merit increases by giving all employees essentially the same merit increases. Your first priority should be to retain and motivate star employees, your second priority to retain and motivate satisfactory employees. Therefore, award the largest salary increases to your stars, much more modest increases to satisfactory performers, and no increases to employees whose performance falls below expectations.

vii) Provide employees with non-financial rewards. Besides cash, employees are motivated by other forms of recognition and rewards. For example, consider establishing an annual trip to reward employees who have achieved certain annual goals. Besides increasing motivation, companysponsored trips build camaraderie and teamwork. How you train, develop and manage your employees also drives retention and performance. However, paying them as well as you realistically can based on their performance, is one of the best ways to heighten their motivation ( Ibid).

\subsection{Motivation and Employee Performance}

Different scholars who have written about motivation of workers generally agree that for most of the workers to perform well, they need incentives. Whetten and Cameron (2007) for instance, have noted that employees are basically similar in their makeup. They all need economic gains or want pleasant climate, or aspire to be self-actualising. By this the duo means that all employees need incentives which can be in form of good salaries, good working conditions or promotion in order to work harder. They further contend that motivation is what drives someone to behave in a certain way or to take a particular action. Motivation, they argue, energises one's goal-oriented behavior. As literature clearly indicates, this motivation can either be divided into intrinsic motivation which comes from rewards inherent to a task or extrinsic motivation which comes from outside (such as reward and coercion).

\subsection{Linking Performance and Incentive Pay}

Incentive pay, tying workers' pay to performance is widely popular. But as dessler (2017) observes, linking pay to performance is easier said than done. As logical as it seems to link pay to performance, most employees do not see a strong connection between pay and performance, and their performance is not particularly influenced by incentive plans they are subjected to. Equally problematic is the fact that some incentives incentivise wrong behavior. He gives an example of an initiative to incentivise 'number of cars sold' in a dealership which might produce high performance in number of cars sold but low per car profit, which inadvertently might lead to undermining the company's strategy to boost dealer profit. Another big reason for incentive plan's often-dismal is the fact that incentives that may motivate some people will not motivate others. Compensation experts therefore argue that managers should understand the motivational bases of incentive plans.

\subsection{Incentives in Zambia's Public Sector}

In reference to Zambia, the Ministry of Education Policy of 1996 (Educating Our Future P. 118) observes that "Terms and conditions of service crucially affect the morale and commitment of teachers". All employees are basically similar in their make-up, and they all want economic gains or aspire to be self-actualising. This means that all employees need incentives which can be in form of good salaries, good working conditions or promotion in order to work harder. Through this National Policy on Education, the Ministry of Education in Zambia has gone further to promise to secure extra incentives for teachers particularly those serving in the rural areas. All these are meant to motivate workers through the provision of incentives.

Furthermore, many authors who have discussed the topic of motivation have stated that all employers are concerned with what they should do with workers in order for them to achieve higher productivity.

With the insights from the Law of individual differences which assumes that people differ in personality, abilities, values, and needs, it becomes even more important to understand the theory of incentives. It also says that different people react to different incentives in different ways thereby making a further demand upon managers to be aware of employee needs and fine-tune the incentives offered to meet employee needs.

Toyoshi-Hamada and Naomi (2007) studied about the Zambian public sector nurses' incentives and motivation in the context of migration in order to establish how to retain Zambian nurses. The 
findings were indicative of declining levels of funding for tertiary-level hospitals having broad implications for the motivation and turnover of their nurses as a result of fewer professional development opportunities, lower allowances, fewer staff and reduced access to essential equipment/drugs. The importance of a lifelong wage structure was also stressed, especially the important role of training, a living wage and an adequate pension. While younger nurses tended to give higher value to training opportunities, senior nurses with family responsibilities needed more financial support. While most nurses interviewed considered it important to meet a minimum standard of living, they were also guided strongly by their professional conscience.

In the findings of her study on a medium-term strategy for enhancing pay and conditions of service in the Zambian civil service, Theodore Valentine made the following observations:

Low remuneration in the Public Service is a major factor contributing to the problem of poor productivity, motivation and recruitment and retention. At a time when Government is seeking efficiency improvements, in part by reducing the size of the civil service, there exist significant staff shortages in a wide range of professional and technical jobs owing to poor pay compared to that available in the private sector and within regional labour markets. Low pay coupled with a poorly constructed internal grading structure and an increments system that is based on the length of service rather than performance, stifles initiative and motivation. A further problem arises from the discrepancies that have crept into wages and allowances paid for comparable jobs in the civil service and of other sectors in the public service. By addressing pay issues it will be possible to secure significant improvements in individual and collective performance and in the quality of service (Toyoshi-Hamada and Naomi, 2017).

The duo's report further suggested that 'Many of the problems associated with the poor quality of public goods and services in Zambia, as in much of Sub Saharan Africa, are related to the low level of remuneration and the lack of an appropriate incentive regime. As pay and incentive problems have persisted for a long period of time, they have given rise to demotivation, low work performance, and low commitment to public service among public servants, reinforcing the low capacity in service delivery institutions, as well as in the production of strategic government outputs".

The authors further argues that the erosion of real pay led to the depletion of scarce human and motivational capital in the public service, giving rise to demoralisation and demotivation of subordinate employees and their supervisors/senior civil servants; reduced work effort, declining levels and expectations in performance; reduced incentives for improving work performance and willingness to accept greater responsibility; the weakening of accountability and controls procedures/mechanisms; diminished ability to recruit and retain qualified managerial, professional and technical manpower; and reduced commitment to public service.

They further argued that allowances are not the best of incentives as "they bear little direct relationship to job performance and productivity, compromising the incentive regime". The study also recognised that it is only when the pay and incentive problems are adequately addressed that realistic creation of an expectation of the process towards the evolvement of an effective, efficient and motivated civil service can be realised. When incentives are not linked to improved performance and not based on an open and objective appraisal mechanism, problems are created within the performance of employees (Ibid).

\section{THEORTICAL FrameWORK}

Several motivation theories that have particular relevance to designing incentive plan can be cited.

\subsection{Herzberg's Two-Factor Theory}

This study was premised on Herzberg's Two-Factor Theory and other support theories for

theoretical reflections. Herzberg stated two types of motivation: Intrinsic and extrinsic motivation. Intrinsic motivation has the self-generated factors that influence people to behave in a particular way or to move in a particular direction. These factors include responsibility, autonomy and scope to use and develop skills and abilities, interesting and challenging work and opportunities for advancement. Extrinsic motivation is what is done to or for people to motivate them and these include rewards such as increased pay, praise, promotion and punishment (Dessler, 2017: 419). 
In this particular theory, Herzberg labours to put across a fundamental question about what people consider as most important about their jobs. He contends that the best way to motivate workers is to consolidate the job so that doing it helps satisfy the person's higher-level needs. Herzberg identifies two factors for this work environment which he calls hygiene and motivators. Within the hygiene (also referred to as extrinsic job factors), he categorises such conditions as salary, incentive pay and inadequate working conditions which can cause frustration and prevent contentment. Satisfaction and dissatisfaction are not opposites but separate constructs, says Herzberg.

Herzberg says the factors ('hygienes') that satisfy lower-level needs are different from those ('motivators') that satisfy or partially satisfy higher-level needs. If hygiene factors (factors outside the job itself, such as working conditions, salary, and incentive pay) are inadequate, employees become dissatisfied. However, adding more of these hygienes (like incentives) to the job (supplying what Herzberg calls "extrinsic motivation") are an inferior way to try to motivate someone, because lowerlevel needs are quickly satisfied. Inevitably the person says, in effect, "I want another raise."

Instead of relying on hygienes, says Herzberg, managers interested in creating a self-motivated workforce should emphasize "job content" or "motivator factors". Managers do this by enriching workers' jobs so that the jobs are more challenging, and by providing feedback and recognition, or in other words by making the job intrinsically motivating. In organisational psychology, intrinsic motivation is motivation that derives from the pleasure someone gets from doing the job or task. It comes from 'within' the person, rather than from externally, such as from financial incentive plan. Intrinsic motivation means that just doing the task provides motivation. Herzberg makes the point that relying exclusively on financial incentives is risky. The employer should also provide the recognition and challenging work that most people desire.

From the motivators (invariably referred to as intrinsic job factors), factors such as job enrichment (which may include recognition, challenging job and feedback) which address higher-level achievement or self-actualisation needs are identified as being important motivators. Below is Herzberg's two factors conceptual framework:

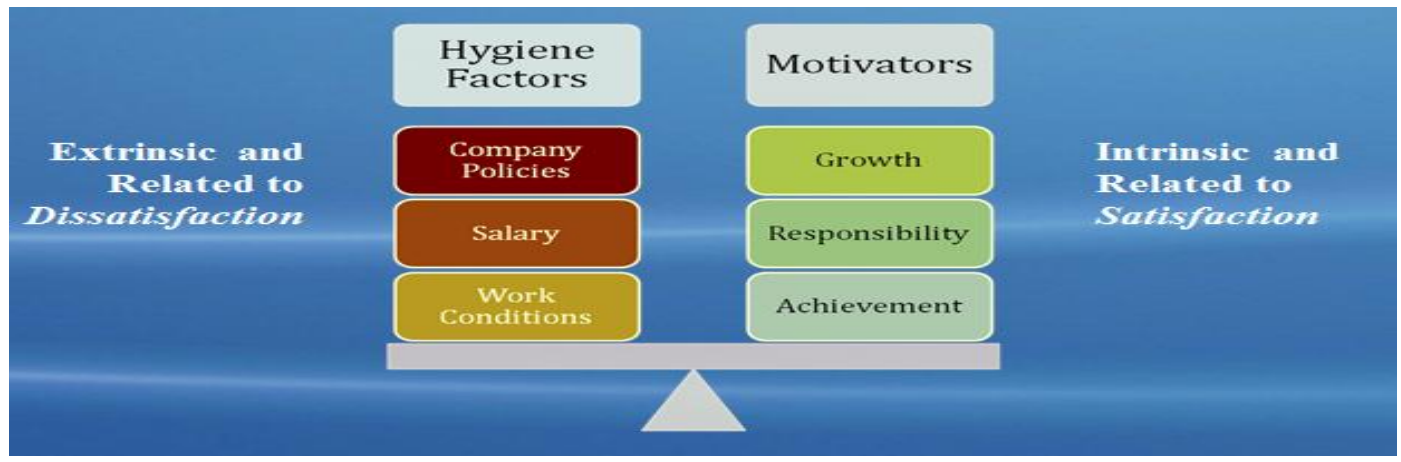

Figure1. Herzberg's Two-Factor Theory (Source: Dessler, 2017: 423)

\subsection{Demotivators and Edward Deci}

Psychologist Edward Deci's work highlights another potential downside to relying too heavily on extrinsic rewards. Extrinsic rewards, he warns, may backfire. Deci found that extrinsic rewards could at times actually detract from the person's intrinsic motivation. The point may be stated thusly: Be cautious in devising incentive pay for highly motivated employees, lest you inadvertently demean and detract from the desire they have to do the job out of a sense of responsibility.

\subsection{Expectancy Theory and Victor Vroom}

In general, people will not pursue the rewards they find unattractive, or where the odds of success are very low. Psychologist Vroom's expectancy motivation theory echoes these common-sense observations. He says a person's motivation to exert some level of effort depends on three things: the person's expectancy (in terms of responsibility) that his or her effort will lead to performance; instrumentality, or the perceived connection (if any) between successful performance and actually obtaining the rewards; and valence, which represents the perceived value the person attaches to the reward. In Vroom's theory: 


\section{Motivation $=(\mathrm{E} \times \mathrm{I} \times \mathrm{V})$,}

Where ' $\mathbf{E}$ ' represents expectancy, ' $\mathbf{I}$ ' instrumentality, and ' $\mathbf{V}$ ' valence. If $\mathrm{E}$ or I or $\mathrm{V}$ is zero or inconsequential, there will be no motivation.

Vroom's theory has three implications on how managers design incentive plans.

- First, if employees don't expect that effort will produce performance, no motivation will occur. So managers must ensure that their employees have the skills to do the job, and believe they can do the job. Thus, training, job description and confidence building and support are important in using incentives.

- Second, Vroom's theory suggests that employees must see the instrumentality of their efforts they must believe that successful performance will in fact lead to getting the reward. Managers can accomplish this, for instance, by creating easy-to-understand incentive plans.

- Third, the reward itself must be of value to the employee. Ideally, the manager must take into account individual employee preferences.

\subsection{Other Theories}

Others scholars who have discussed the concept of motivation are the proponents of reinforcement theories. They have noted that much as it is indisputable that workers need incentives in order to work harder, the act of motivating workers is a complex phenomenon. This is because the behaviour of a human being is difficult to predict. Slavin (2009) observes that:

...one reason that reinforcement history is an inadequate explanation for motivation is that human motivation is highly complex and context-bound. With very hungry animals we can predict that food will be an effective reinforcement. With humans, even hungry ones, we can't be sure what will be a reinforcer and what will not because the reinforcing value of most potential reinforcers is largely determined by personal or situational factors (p.298).

From Slavin's quotation above it is implied that it is not always that incentives given to workers may motivate them. This is so because employers may not predict with precision what workers really need in order to be motivated. Therefore, if what is referred to as incentive is not the appropriate reinforcer a worker needs, it may not serve the intended purpose.

Meanwhile Slavin's explanation can be classified under the content theories of motivation which explains the dynamics of employee's needs such as why people have different needs at different times. The content theories further explain motivation needs either as single or group needs. They also attempts to identify particular needs and rewards which influence worker behaviour as individuals or in groups.

In contrast to content theories are the process theories which lay emphasis on the internal choices workers make vis-a-vis the incentives to motivate them. The theories explain that workers motivation arise when they are fully aware of their motives and actions and of the risks involved and make plans guided by their expectations.

From this explanation, the theories emphasise that it is the workers who should determine the incentives taking into account motives, actions and the risks involved in their jobs and not the employer. One difficulty challenge that can be seen in the implementation of these theories is that the workers might demand for incentives which might be too costly to meet and also not corresponding with their productivity. This is because the rationale beyond incentives shifts from productivity to motives, actions and risks involved in the course of executing duties.

In another development, there are authors who have some apprehensions about giving incentives. Even though they have no quarrel with giving incentives to workers, their main concern is about the value the incentives to be given to the workers should have. They argue that in understanding and applying motivation theory, the aim is to obtain added value through people in the sense that the value of their output exceeds the cost of generating it (Ibid). 
What Slavin is saying is that employers are free to give incentives to their workers but their cost should not be more than the value of their output because the motive of giving incentives will be defeated.

\subsection{Conclusion on Literature Survey}

The reviewed literature has given us the insights and the dynamics about giving incentives in order to motivate workers and enhance productivity. The literature clearly states that motivation is a necessity of higher productivity even though it is not easy to determine the reinforcers which can induce productivity as different individual workers need different incentives.

\section{MeThodology}

From a study population of 200 employees, a sample of thirty respondents was drawn using a probability sampling method, which comprised 50\% academic staff and 50\% support staff. Fifty-four per cent of the sample constituents were males while $46 \%$ were females. Data was collected using a Semi-structured questionnaire for the twenty-three respondents, while a list of eight open ended questions was used as an interview guide for the seven 'key' informants, in addition to documentary evidence. Data were analysed using frequencies and percentages. Additionally, descriptions, explanations and making of inferences were used in the analysis of data.

\section{RESUlT AND DISCUSSION}

To the question "What do you understand by the term Incentive", $89 \%$ staff gave responses that indicated that they understood the meaning of the term. Even though they defined the term differently in their own ways, respondents demonstrated the common understanding that incentives were some kind of motivations needed for workers to continue working in an organisations; some kind of a rewarding mechanism that was either in the form of promotions or direct financial payments such as increase in wages, salary increment, commissions, et cetera. Respondents further understood incentives as something aimed at ensuring that workers delivered results in accordance with the expectations of their controlling officers.

Having understood incentives in such contexts, respondents subsequently did acknowledge the relationship between incentives and workers performance on the job.

Respondents, however, noted that there was only one form of incentive at Kwame Nkrumah University at the time of study, and that was through annual salary increment which was effected to all employees not based on performance.

With regard to promotion on job as part of incentive, respondents said this was not yet implemented at Kwame Nkrumah University, adding that in their own understanding, this was one of those things that were lined-up to be done in due course, since the institution had just come out of massive transformation. This also applied to the promotion criteria, whose mechanisms were just being finalised at the time of the study.

Subsequent questions which received similar responses as the ones above, i.e. based on the nonavailability of mechanisms at the time of the study, included the one that sought to find out "whether the current motivational incentives met the intended purpose", and the one that sought to enquire on "whether rewards to workers were administered contingent upon effective performance".

It was generally observed that at the time of study, the relationship between pay and performance (referred to as the incentive regime or system) was still not adequately elaborated; salary differentials needed further improvements in order to reward and motivate good performance. Annual increments were awarded almost automatically and were considered as a right, with no distinction between excellent, good and bad performers. The promotion criteria were not yet clearly availed to the employees, and there appeared to be little distinction made between mediocrity and merit/competence.

One respondent observed that employees were generally demotivated partially due to lack of adequate incentives, a situation which she feared if not given attention would result in inefficiency and poor service delivery. The observed fears in this respondent seem to be consistent with Toyoshi-Hamada 
and Naomi's 2017 report which suggested that many of the problems associated with the poor quality of public goods and services in Zambia, as in much of Sub Saharan Africa, are related to the low level of remuneration and the lack of an appropriate incentive regime and which, as pay and incentive problems persist for a long period of time, give rise to demotivation, low work performance, and low commitment to public service among public servants.

A Head of one Social Sciences Departments observed the difficulty in attracting certain levels of highly qualifies manpower in the University on reasons largely based on unattractive incentives. He noted: "Inadequate incentives lead to the depletion of scarce human and motivational capital among employees, giving rise to a demoralised workforce". He said this was mostly common among subordinate employees. Other similar responses on the effect of poor incentives cited by respondents included reduced work effort, declining levels and expectations in performance; reduced willingness to accept greater responsibility; the weakening of accountability and controls procedures / mechanisms; diminished ability to recruit and retain qualified managerial, professional and technical manpower; and reduction in commitment to work.

All in all, 93\% respondents expressed dissatisfaction at the current work environment in as far as incentivising of workers and rewarding systems were concerned, as they looked up to the future for possible improvements. As some of the responds put it, a focus on incentivising workers was supposed to be a necessary future undertaking, among other priorities, if the institution was to avoid such eminent vices as the feelings of resentment and despondency among employees at the work place, as these would be detrimental to achieving efficiency in the service delivery at the institution.

By and large, all respondents in the study seemed to have been only comforted by the promising future that the lacking mechanisms in addressing the motivational needs of employees at the institution would soon be addressed by managements. A number of them (77\%) had embarked on initiatives of coming up with other forms of income at home to supplement their salaries.

\section{CONCLUSION AND RECOMMENDATIONS}

\subsection{Conclusion}

This study attempted to find out whether employees at Kwame Nkrumah University in Zambia were incentivised enough to enhance quality service delivery. Based on the gathered data, the study established that the majority of employees at the institution were not satisfied with the current efforts put in place by management to motivate them. It was found that the University had not devised any incentive mechanism at the time of the study, and part of the reasons advanced was that the institution had just come out of the massive transformation with a lot of mechanisms, policies and systems still in the process of being developed. This scenario seemed to have left the majority of staff with no option but to endure the situation and exercise patience.

\subsection{Recommendations}

Based on the findings of the study, the researcher recommends the following:

i) The University should consider devising mechanisms to give incentives to its employees as a top priority.

ii) Incentives should be administered to employees contingent upon their effective performance.

\section{REFERENCES}

[1] Chakraborty, A. et.al. (2009) "The relationship between incentive and compensation," at http://www. ince ntivecompensation.org/, retrieved: 19/07/2020

[2] Cole, G.A. (2002). Personnel and Huamn Resource Management, Fifth Edition. London: Cengage Learning EMEA.

[3] Dessler, G. (2017). Human Resource Management, $15^{\text {th }}$ Edition. England: Pearson Education.

[4] Slavin R.E., (2009) Educational Psychology ( $9^{\text {th }}$ Edition) Upper Saddle River, New Jersey:

[5] Theodore R. Valentine, Ph.D. Crown Consultants International.Times Print park (Z) Lusaka. 
[6] Toyoshi-Hamada, Naomi; (2007) Zambian public sector nurses' incentives and motivation in the Volume 61, Issue 4, July-August 2009, Pages 295-311.

[7] Whetten, D. A. \& Cameron, K. S., 2007. Developing Management Skills, 7th ed., New Jersey: Prentice Hall.

\section{AUTHOR'S BIOGRAPHY}

Dr. Joseph Kayuni Hachintu, is currently the Director of Research and Postgraduate Studies, former

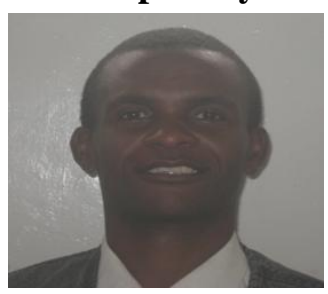

Quality Assurance Head of Department, a researcher and a lecturer in Religious Studies at Kwame Nkrumah University in Zambia. He holds a doctoral degree in Religious Studies from the University of South Africa and has been teaching Religious Studies for more than twelve years now. Besides, Joseph has published Journal articles in international Journals and contributed book chapters to international publications. He has since published a book entitled "Religion, Kusalazya Cleansing Ritual and the Coming of the HIV/AIDS in Chikankata District" which is a fruit of reflections which developed from an Essay of his Master's degree fieldwork. Joseph's extensive research interest covers Religion and Society, Education and Society, Sexuality, HIV/AIDS and Quality Education Delivery.

Citation: Joseph Kayuni Hachintu, PhD. "Enhancing Quality Services Delivery Through Staff Motivation at Kwame Nkrumah University" International Journal of Humanities Social Sciences and Education (IJHSSE), vol 7, no. 9, 2020, pp. 138-147. doi: https://doi.org/10.20431/2349-0381.0709014.

Copyright: (c) 2020 Authors. This is an open-access article distributed under the terms of the Creative Commons Attribution License, which permits unrestricted use, distribution, and reproduction in any medium, provided the original author and source are credited. 